\title{
Effects of bail activation sequence and feed availability on cow traffic and milk harvesting capacity in a robotic rotary dairy
}

\author{
R. Kolbach, ${ }^{* 1}$ K. L. Kerrisk, ${ }^{*}$ S. C. Garcia, ${ }^{*}$ and N. K. Dhand $\dagger$ \\ ${ }^{*} \mathrm{MC}$ Franklin Laboratory (CO4), and \\ †J. L. Shute Building (C01), Faculty of Veterinary Science, The University of Sydney, Private Mailbag 4003, Narellan, \\ New South Wales 2567, Australia
}

\section{ABSTRACT}

This study was conducted to investigate the effects of different bail activation sequences in combination with feed availability on cow traffic and harvesting capacity in a novel prototype robotic rotary (RR; DeLaval AMR, Tumba, Sweden). The RR can milk up to 50 cows/h. However, in voluntary cow traffic systems, the number of cows presenting may be low at certain times of the day (or during certain months or seasons in seasonal calving systems). In these circumstances, the ratio of active bails to the number of cows available may be undesirably high, with consequential negative effects on system efficiency and milk quality (the RR does not flush individual units automatically after each milking). Activating only $50 \%$ of the bails may be a management strategy chosen to cope with periods of underutilization. Four treatments with a total activation of $50 \%$ of bails [ 8 bails with activation sequences of $8,4,2$, or 1 consecutive bail(s)], with or without the presence of feed on the RR, were observed during sixteen 4 -h observation periods after a system wash. The absence of feed resulted in a significant increase in the proportion of available bails remaining idle, but no significant differences were observed across the 4 bail activation sequences. Overall, the effect of bail activation sequence on cow traffic was negligible, but the sequences that had more consecutive bail activations resulted in more robot operations being conducted simultaneously and more milk being harvested per minute of robot operation time. A feeding function upon entry to the RR platform, in combination with bails activated sequentially, would lead to a more efficient use of the RR.

Key words: automatic milking system, dairy, robotic rotary, harvesting rate

Received January 11, 2012.

Accepted December 13, 2012.

${ }^{1}$ Corresponding author: rkol5087@uni.sydney.edu.au

\section{INTRODUCTION}

Farms in predominantly grazing countries have begun to install automatic milking systems (AMS; K. L. Kerrisk, personal communication). In general, these farms have larger herds, lower milk yields, and higher efficiency of labor utilization compared many of the intensively fed and housed farming systems in which AMS are typically installed. In response to the specific requirement of larger scale, pasture-based systems, a novel robotic rotary (RR; DeLaval Automatic Milking Rotary-AMR, Tumba, Sweden) has been developed and was installed at the Elizabeth Macarthur Agricultural Institute (Camden, New South Wales, Australia) in 2009. The RR was initially developed to be able to milk a large herd of cows automatically with a lower capital investment compared with the existing, singleand multi-box AMS technology.

The prototype RR is capable of carrying out approximately 50 cow milkings per hour with the installation of 2 robotic arms: (1) a teat preparation robot (teat preparation module; TPM), and (2) a teat cup attachment robot (automatic cup attacher; ACA). To enable the RR to achieve such high levels of throughput (compared with a single-box robot), the robotic arms remain stationary while the rotary platform rotates the cow around from the entry point to the exit point in a stop-start operation (see Figure 1). The installation of multiple robotic arms enables 2 cows to be simultaneously premilked and have teat cups attached, resulting in a higher potential throughput (compared with existing commercial AMS units). Kolbach et al. (2013) reports attachment times of $75 \mathrm{~s}$ per cow, which equated to a potential throughput of 48 cows/h with the 16-bail prototype RR. This level of throughput was reliant on consistent and uninterrupted cow traffic onto the platform.

Two of the key functionality differences between existing commercial AMS units and the RR are (1) The $\mathrm{RR}$ has no automated washing or rinsing functionality; and (2) the RR does not have an integrated controlled feeding function. Incorporating these 2 functions may 


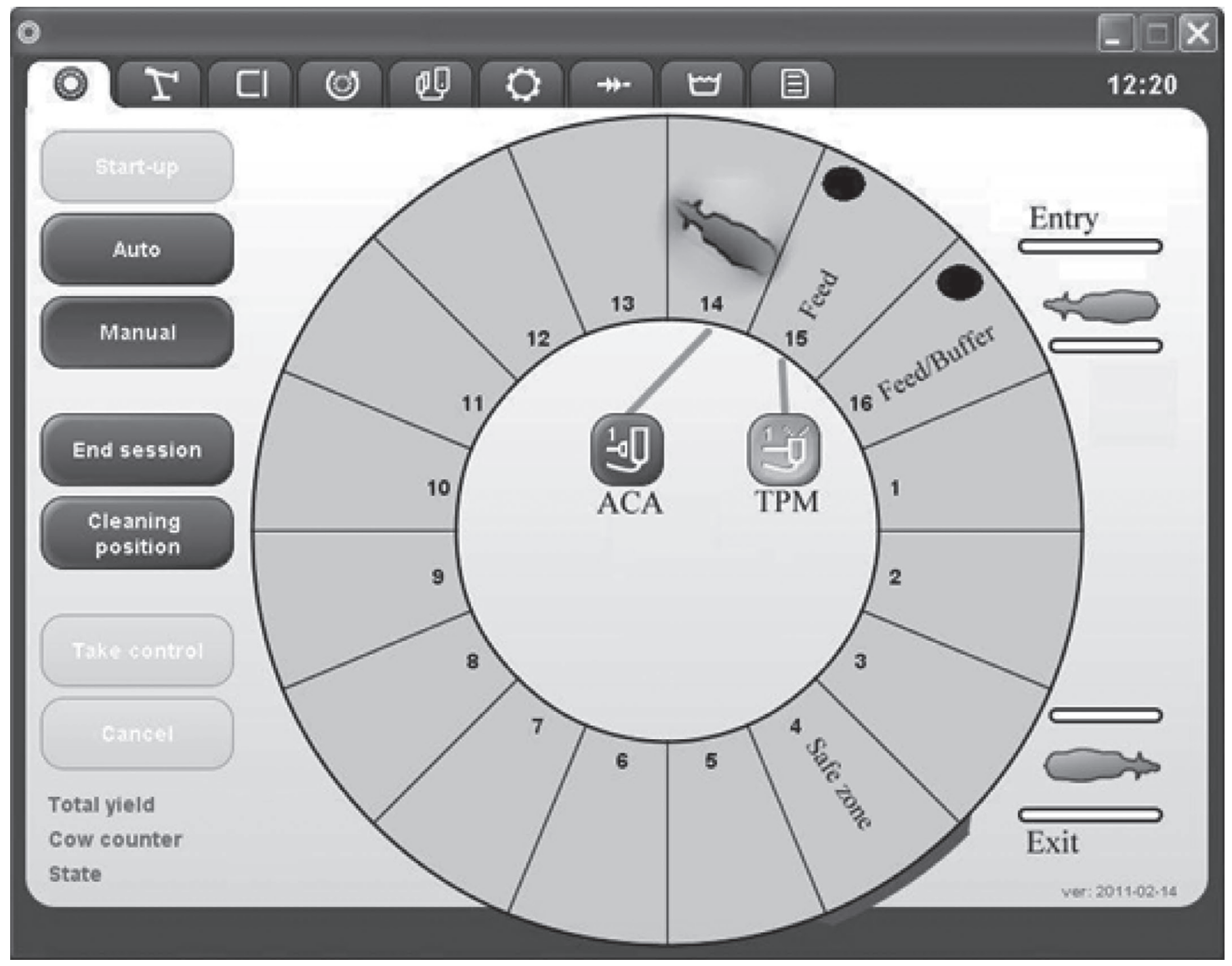

Figure 1. Schematic of the robotic rotary showing the entry to the rotary, the buffer bail zone (bail 16), teat preparation module (TPM), automatic cup attacher (ACA), exit from the rotary platform, safe zone (bar shown adjacent to bail 4), and the feed available at the TPM and buffer bail positions (bails 15 and 16, feed bin position indicated as a black circle). Schematic graphic user interface courtesy of DeLaval AMR (Tumba, Sweden).

be technically achievable, but the cost of the additional automation may be prohibitive to adoption. The RR was initially developed to create an economically attractive solution for large-scale farms to automate milk harvesting tasks. The financial advantage of the RR, compared with traditional AMS, will likely be eroded if additional functionalities are incorporated. The first commercial versions of the equipment will not have these 2 functions (R. Mulder, DeLaval, Hamilton, New Zealand, personal communication).

The lack of automated washing will create the greatest application challenge when the system is being underutilized with regard to number of cows in milk or number of milkings conducted per day. To cope with the potential effect of individual used bails being idle (and the associated increase in bacteria count) an auto-disabling function is available, which allows the user to set the idle time limit before the used bail is deactivated. During periods of underutilization, the ratio of cows to active bails will be low and bails will have an increased risk of being deactivated. In extreme circumstances, this will result in very low numbers of active bails within a few hours after a system wash has been implemented. A potential solution is to increase the ratio of cows to active bails by deactivating some bails. This will reduce the risk of bails being automatically deactivated while also ensuring that clean bails can be manually activated either in person or remotely, 
as required. This should allow the system to be operated efficiently throughout extended periods (up to 12 h) between system washes.

It has been reported that cows, as animals of routine, are conditioned by circumstances surrounding milking (Cowie, 1983 cited by Stefanowska et al., 1999). It is possible that the configuration of active bails (e.g., alternate, or groups of consecutive bails referred to as "bail activation sequence" throughout this manuscript) may affect predictability for the cows, thereby affecting cow traffic onto the platform. In addition, the efficiency of the robotic devices may also be affected by reducing the likelihood of robotic arm actions being conducted simultaneously.

The lack of in-bail feeding has the potential to affect cow traffic and the speed at which cows traffic onto the platform. Numerous reports in the literature have shown the effect of concentrated feed (Halachmi et al., 2005; Bach et al., 2007), and even pasture allocation (Jago et al., 2002; Davis et al., 2007), as motivators for cow traffic.

In this study we hypothesized that a consecutive bail activation sequence and feed available on entry to the $\mathrm{RR}$ would result in improved cow traffic and in more efficient robot operation, thereby improving the overall number of cows milked per hour and the milk harvesting rate of the $R R$.

\section{MATERIALS AND METHODS}

\section{Experimental Design}

The RR conducts a defined process to carryout milk harvesting before a cow is released from the RR platform. See Appendix 1 for a detailed description of the $\mathrm{RR}$ milking process. The milking process in the 16-bail prototype RR with 2 robots is, in brief, as follows (refer to Figure 1): (1) a cow is recognized upon entry; (2) if the "buffer zone" (numbered as bail 16 in Figure 1) is already occupied, the cow waiting at the gate will not gain access until the next available bail rotates to the entry gate position (bail 1 in Figure 1); (3) after entering, the cow is rotated toward the TPM for premilking teat preparation (shown as bail 15 in Figure 1); (4) the cow is rotated from the TPM to the ACA where teat cups are attached (shown as bail 14 in Figure 1); (5) the cow is rotated toward the exit of the RR platform in a step-wise fashion.

When a cow is still being milked as she enters the "safe zone" (shown as the gray bar alongside bail 4 in Figure 1), rotation is prevented and all other actions are paused until the milking of that cow is complete. When no cows enter an available bail in the buffer zone, the system waits for up to $90 \mathrm{~s}$ (programmable time) after all robot functions are complete and milking of the cow in the safe zone is completed before a step time-out occurs (available bail remains unutilized).

During the trial, 160 mixed breed (Holstein $\times$ Illawarra, Holstein-Friesian and Illawarra) dairy cows were managed as a single voluntarily trafficking herd and milked with a prototype RR. The herd consisted of $30 \%$ primiparous and $70 \%$ multiparous animals, with an average of 3 lactations (parity range 1-10; median lactation number 2; SD 2.1) and 137 DIM (median 140 d; SD 88.9 d). At the commencement of the trial, the 7 -d average production level of the cows was $18.5 \mathrm{~kg} /$ cow per day (median $17.8 \mathrm{~kg}$; SD $6.3 \mathrm{~kg}$ ), average yield was $10.8 \mathrm{~kg} /$ cow per milking (median $17.8 \mathrm{~kg}$; SD 6.3 $\mathrm{kg}$ ), and average milking frequency was 1.7 milkings/ cow per day (median 2; SD 0.4). All the cows had up to 18 mo of intermittent, regular exposure to and experience with the RR before the start of the trial. The herd was milked by the RR exclusively for 6 wk before the commencement of the trial and during the entire data collection period. The cows had access to a day pasture allocation from 0830 to $1800 \mathrm{~h}$ and a night pasture allocation from 1800 to $0830 \mathrm{~h}$. Total feed allocation target was $20 \mathrm{~kg}$ of DM/cow per day, with $6 \mathrm{~kg}$ of DM/ cow per day supplied as partial mixed ration (PMR) on the post-milking feedpad. The PMR consisted of 3.7 $\mathrm{kg}$ of maize silage, $1.3 \mathrm{~kg}$ of pelleted concentrate $(18 \%$ protein), $0.5 \mathrm{~kg}$ of oaten hay, $0.4 \mathrm{~kg}$ of lucerne silage, and $0.1 \mathrm{~kg}$ of oaten silage (all as $\mathrm{kg}$ of $\mathrm{DM} / \mathrm{cow}$ per day). As presence of feed was also investigated during this trial, during "feed-on" periods, cows were given an additional small allocation of pelleted concentrate $(18 \%$ protein) in the first 2 bails of the RR (total $\sim 0.3 \mathrm{~kg} /$ cow per milking; bails 15 and 16 as shown in Figure 1).

Cow traffic refers to the voluntary movement of cows around the farm resulting in milkings without human intervention (with the exception of clearing cows from paddocks twice daily). To test the effect of the different bail activation sequences on cow traffic onto the $\mathrm{RR}$ and robotic harvesting efficiency, 4 different bail activation sequence settings were tested (Figure 2): (1) 8 consecutive bails activated ( 1 set of 8 bails; $\mathbf{1} \times \mathbf{8}) ;(2)$ 2 sets of 4 consecutive bails activated $(\mathbf{2} \times \mathbf{4})$; (3) 4 sets of 2 consecutive bails activated $(\mathbf{4} \times \mathbf{2})$; and (4) every alternate bail activated $(\mathbf{8} \times \mathbf{1})$.

To determine the effect of the availability of feed (pelleted concentrates available to cows on entry to the RR; Figure 1) on cow traffic onto the RR, feed availability (no feed vs. feed) was tested in combination with the 4 different bail activation treatments. A 5 -d adjustment period was implemented when the feed was turned off before starting observations, and a 2-d adjustment period was given when feed was reoffered after the nonfeeding treatment. 


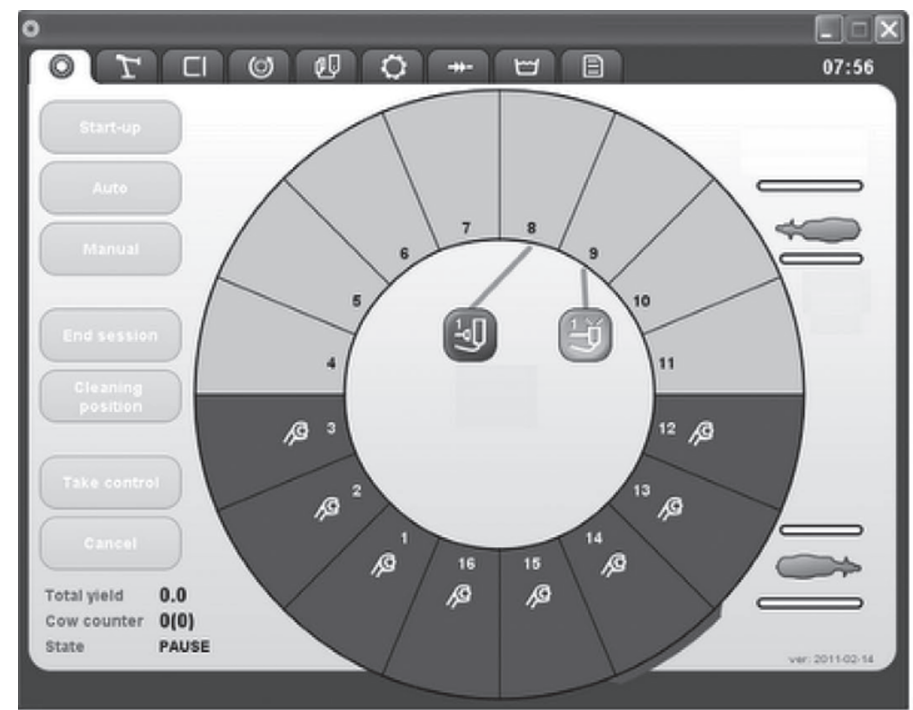

$1 \times 8$

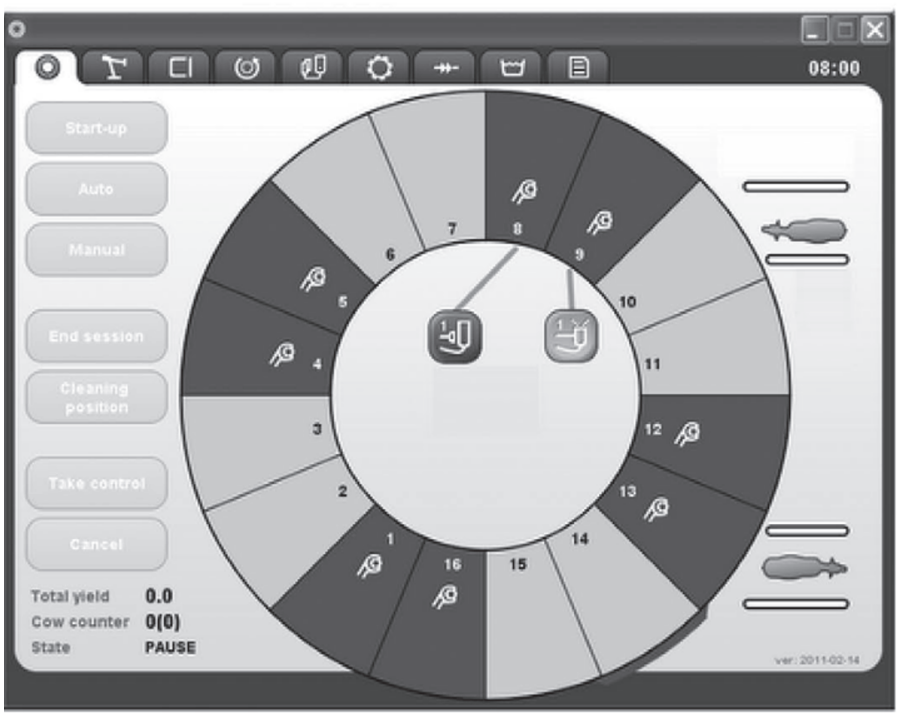

$4 \times 2$

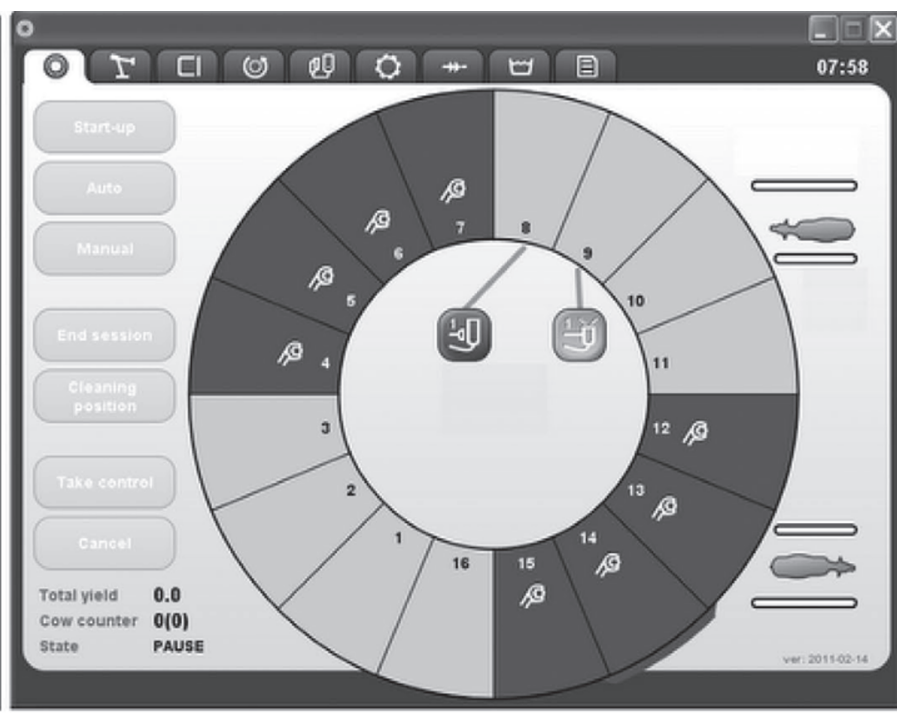

$2 \times 4$

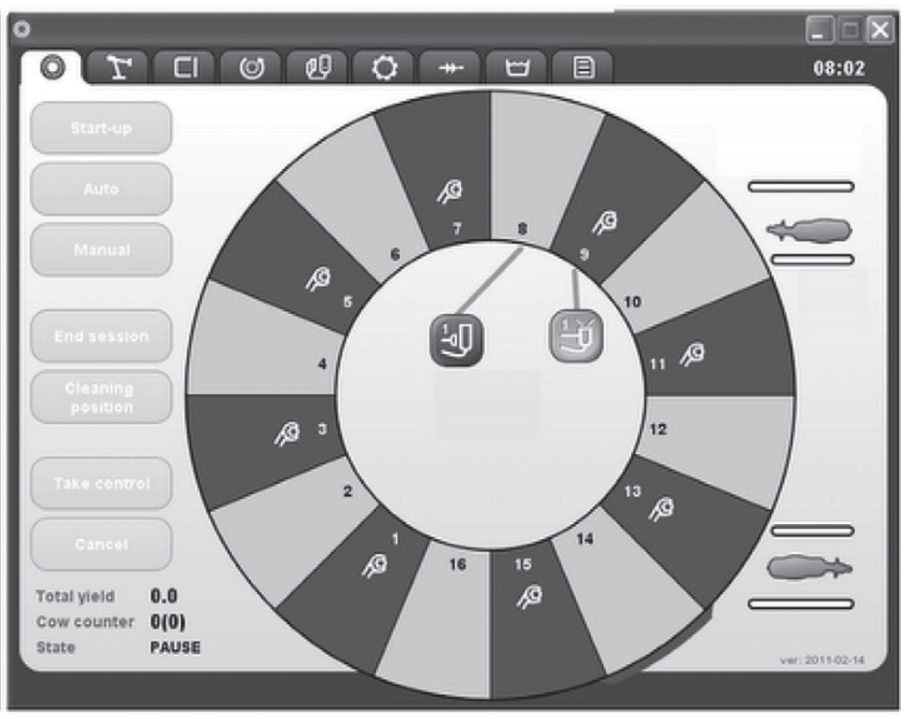

$8 \times 1$

Figure 2. Four bail activation sequence treatments tested, where dark-colored bails are inactive and light-colored bails are active: 8 consecutive bails activated $(1 \times 8) ; 2$ sets of 4 consecutive bails activated $(2 \times 4) ; 4$ sets of 2 consecutive bails activated $(4 \times 2)$; and every alternate bail activated $(8 \times 1)$. Schematic graphic user interface courtesy of DeLaval AMR (Tumba, Sweden).

Each treatment was randomly selected per block and was repeated and observed twice, with and without feed (Table 1). A block was defined as the period of consecutive days when observations were conducted. Every block was designed to contain 4 treatments in the initial study design. However, due to a technical failure (a breakdown), the first block contained only 2 treatments; the 2 treatments missed in this block were applied in the fourth block. Therefore, block 1 had 2 observation sessions, blocks 2 and 3 had 4 observation sessions, and block 4 had 6 observation sessions. In total, sixteen 4-h observations were conducted with each session commencing in the morning after a system wash at approximately $0700 \mathrm{~h}$.

The following data were collected manually and recorded during the observation periods:

(1) The occupancy of each bail on each rotation (supported by electronic data).

(2) Cow-related idle times, which were defined as any time when the system was capable of conducting a certain action (e.g., teat cleaning, cup attaching, or platform rotation) but that action was delayed as a result of cow traffic, milking 
Table 1. Trial design

\begin{tabular}{lrcc}
\hline & & \multicolumn{2}{c}{ Bail treatment $^{1}$} \\
\cline { 3 - 4 } Block & Day & No feed & Feed \\
\hline $1^{2}$ & 1 & & $8 \times 1$ \\
& 2 & & $1 \times 8$ \\
& 3 & $4 \times 2$ & \\
& 4 & $8 \times 1$ & \\
3 & 5 & $1 \times 8$ & \\
6 & $2 \times 4$ & \\
& 7 & $1 \times 8$ & \\
& 8 & $4 \times 2$ & $2 \times 4$ \\
4 & 9 & $2 \times 4$ & $8 \times 2$ \\
& 10 & $8 \times 1$ & $4 \times 2$ \\
& 11 & & $2 \times 4$ \\
& 12 & & $1 \times 8$ \\
\hline 13 & & \\
14 & & \\
& 15 & & \\
& 16 & & \\
\hline
\end{tabular}

${ }^{1}$ Treatments: $8 \times 1=$ every alternate bail activated; $1 \times 8=8$ consecutive bails activated; $2 \times 4=2$ sets of 4 consecutive bails activated; $4 \times 2$ $=4$ sets of 2 consecutive bails activated (Figure 2).

${ }^{2}$ Block 1 had only 2 treatments due to a system breakdown. The missing treatments were applied in block 4 .

duration, or a technical function. Three cowrelated idle factors were recorded: (a) a cow did not walk on the platform and a step time-out occurred; (b) a cow hesitated and was standing in the entry gate preventing platform rotation; and (c) a cow did not walk on the RR during the buffer period (period during which at least one robot was conducting an action and the platform could not rotate) but walked onto the platform before a step time-out occurring.

(3) Two system factor idle times were recorded: (a) if the entry gates did not allow a cow to enter the system during the buffer period; and (b) rotation was prevented due to a cow still being milked (milking in progress) when it reached the exit point of the platform. The last consecutive active bail in any sequence was denied a buffer period. By default, therefore, bails 3, 7, 11, and 15 in treatment $4 \times 2$; bails 3 and 11 in treatment $2 \times 4$; and bail 11 in treatment $1 \times 8$ did not have a buffer period (referring to bails shown in Figure 2). Milking in progress was deemed a system factor idle time because it was influenced strongly by the bail activation sequence. Although the potential for this to occur with slow milking cows in any bail, the likelihood was greatest for treatments $1 \times 8$ and $2 \times 4$, as cows entering the last of the consecutive active bails were rotated more promptly to the exit area.

The step time-out time was set at $90 \mathrm{~s}$ for the duration of the trial, and all 4 treatment groups had 8 bails active during the entire 4-h observation sessions. Bails remaining idle were not disabled during the observation periods. This decision was made to allow the designated bail activation sequence (treatments) to be maintained for the duration of each observation period.

\section{Statistical Analyses}

Outcome Variables. Treatment effects were measured on 4 binary outcome variables: (1) utilization of available bails; (2) occurrence of an idle time due to cow factors (cow-idle time: yes or no); (3) occurrence of an idle time due to system factors (system idle time: yes or no); and (4) 3 quantitative outcome variables: (a) duration of cow-idle time; (b) duration of system idle time; and (c) harvesting rate $(\mathrm{kg} / \mathrm{min}$ robot operation time).

Harvesting Rate. Electronic data collected by the VMSClient management program (DeLaval, Tumba, Sweden) were used to calculate the total milk yield harvested per observation period, which was then used for calculation of the harvesting rate:

$$
\begin{gathered}
\text { Harvesting rate }(\mathrm{kg} / \mathrm{min} \text { robot operation time })= \\
\text { Total yield per observation period } / \\
\text { robot operation time. }
\end{gathered}
$$

Robot operation time was the total time of the 4-h observation period that the RR was capable of operating, minus idle times related to cow factors. Cow-idle times were deleted from the robot operation times to generate a harvesting rate that is calculated in a similar manner to that commonly reported with single- and multi-box AMS (milk harvested/min of crate occupancy). As a parameter, harvesting rate gives the reader an indication of the potential harvesting rate of the system, assuming cows are presenting themselves onto the $\mathrm{RR}$ without delay. To calculate system harvesting rate, all data were summarized per hour of the observation.

\section{Explanatory Variables}

Treatment and feed availability were used as explanatory variables in all analyses.

\section{Statistical Models}

Data were analyzed with SAS software (release 9.2, 2002-2008, SAS Institute Inc., Cary, NC). Binary outcome variables were analyzed using generalized linear mixed models (GLMM) and the continuous outcome variables using REML. Bail activation sequence, feed 
Table 2. Proportion of available bails (active bails passing the entry point) occupied by cows per treatment, with or without feed available

\begin{tabular}{lccccc}
\hline & \multicolumn{4}{c}{ Treatment $^{1}$} \\
Feed \\
\cline { 2 - 5 } availability & $1 \times 8$ & $2 \times 4$ & $4 \times 2$ & $8 \times 1$ & Overall \\
\hline No feed & 0.60 & 0.59 & 0.65 & 0.54 & 0.59 \\
Feed & 0.88 & 0.94 & 0.89 & 0.89 & 0.90 \\
Overall & 0.74 & 0.77 & 0.76 & 0.71 & 0.74
\end{tabular}

${ }^{1}$ Treatments: $1 \times 8=8$ consecutive bails activated; $2 \times 4=2$ sets of 4 consecutive bails activated; $4 \times 2=4$ sets of 2 consecutive bails activated; $8 \times 1=$ every alternate bail activated (Figure 2).

availability, and their first-order interactions were included as fixed effects, whereas block and day within block were included as random effects in all models. Nonsignificant terms were deleted from the final model, but treatment and feed availability, the variables of interest, were retained in the final model even if not significant. The interaction terms for all models were found to be nonsignificant and were deleted.

For analyses of cow- and system-related idle times, the observations where no idle time occurred were excluded and then the outcome variables were log-transformed to normalize their distributions. If the assumptions were not valid even after log-transformation, Poisson regression or negative binomial regression models were fitted instead, as appropriate.

\section{RESULTS}

\section{Descriptive Results}

During the observation periods, the average number of cows milked per hour was $14.4 \pm 4.2($ mean $\pm \mathrm{SD}$ ) with maximum throughput peaking at 23 cows within a 1-h interval. Average milk harvesting level was $175 \pm$ $52 \mathrm{~kg}$ of milk per hour (peak $280 \mathrm{~kg}$ ).

Regardless of the sequence of bails enabled or disabled, the proportion of available bails that were actu-
Table 3. Number of events and total duration (min) of cow and system-related idle times for all 16 observation sessions, shown per treatment

\begin{tabular}{lcccccc}
\hline & \multicolumn{2}{c}{ Cow idle } & & \multicolumn{2}{c}{ System idle } \\
\cline { 2 - 3 } \cline { 5 - 6 } $\begin{array}{l}\text { Bail } \\
\text { treatment }\end{array}$ & $\mathrm{n}$ & Time & & $\mathrm{n}$ & Time \\
\hline $1 \times 8$ & 120 & 192.3 & & 69 & 24.9 \\
$2 \times 4$ & 118 & 175.7 & & 97 & 15.7 \\
$4 \times 2$ & 137 & 174.3 & & 164 & 38.8 \\
$8 \times 1$ & 112 & 173.3 & & 8 & 1.7 \\
\hline
\end{tabular}

${ }^{1}$ Treatments: $1 \times 8=8$ consecutive bails activated; $2 \times 4=2$ sets of 4 consecutive bails activated; $4 \times 2=4$ sets of 2 consecutive bails activated; $8 \times 1=$ every alternate bail activated (Figure 2 ).

ally used during all the observed milkings did not differ among treatments $(P>0.05$; range 71 to $77 \%$; Table 2 ). However, the effect of feed on the proportion of available bails being used was significant $(P<0.05$; 59 vs. $90 \%$ for no feed vs. feed, respectively). Table 3 shows the incidence and total duration of idle time events recorded across the 16 observation sessions related to cow and system factors.

\section{Cow Traffic onto the RR: Utilized Versus Not Utilized Bails}

The probability of an available bail being utilized was affected by feed availability but not by the bail activation treatment (Table 4). The bails were 5.7 times more likely to be utilized when feed was available compared with when it was not available.

\section{Cow Factors Resulting in Idle Time}

The availability of feed significantly affected the occurrence of cow-related idle times (Table 5). Idle time events were about 7 times less likely to occur if feed was available compared to when feed was not available. However, bail activation sequence did not have a significant effect on the occurrence of idle times (Table 5).

Table 4. Final generalized linear mixed model for the binary outcome variable utilization of available bails by cows trafficking onto the robotic rotary platform ${ }^{1}$

\begin{tabular}{llcccc}
\hline Effect & Category & $\begin{array}{c}\text { Parameter } \\
\text { estimate }\end{array}$ & $\mathrm{SE}$ & $\begin{array}{c}\text { Odds ratio } \\
(95 \% \mathrm{CI})\end{array}$ & $P$-value \\
\hline Intercept & & 0.42 & 0.41 & & 0.93 \\
Bail treatment $^{2}$ & $1 \times 8$ & 0.00 & & & \\
& $2 \times 4$ & 0.07 & 0.38 & $1.07(0.51,2.54)$ & \\
& $4 \times 2$ & -0.07 & 0.38 & $0.94(0.45,1.95)$ & \\
Feed availability & $8 \times 1$ & -0.17 & 0.36 & $0.84(0.41,1.71)$ & 0.0004 \\
& No feed & 0.00 & & & \\
& Feed & 1.74 & 0.50 & $5.7(2.16,15.01)$ & \\
\hline
\end{tabular}

${ }^{1}$ Block and day nested in block were included as random effects.

${ }^{2}$ Treatments: $1 \times 8=8$ consecutive bails activated; $2 \times 4=2$ sets of 4 consecutive bails activated; $4 \times 2=4$ sets of 2 consecutive bails activated; $8 \times 1=$ every alternate bail activated (Figure 2 ). 
Table 5. Final generalized linear mixed model for the binary outcome variable - occurrence of idle time events due to cow factors ${ }^{1}$

\begin{tabular}{llcccc}
\hline Effect & Categories & $\begin{array}{c}\text { Parameter } \\
\text { estimate }\end{array}$ & SE & $\begin{array}{c}\text { Odds ratio } \\
(95 \% \text { CI })\end{array}$ & $P$-value \\
\hline Intercept $^{\text {Bail treatment }}{ }^{2}$ & & 0.20 & 0.43 & & \\
& $1 \times 8$ & 0.00 & & & \\
& $2 \times 4$ & 0.19 & 0.48 & $1.21(0.47,3.14)$ & \\
& $4 \times 2$ & 0.60 & 0.48 & $1.83(0.72,4.69)$ & \\
Feed availability & $8 \times 1$ & 0.13 & 0.48 & $1.41(0.45,3.14)$ & $<0.0001$ \\
& No feed & 0.00 & & & \\
\hline
\end{tabular}

${ }^{1}$ Block and day nested in block were included as random effects.

${ }^{2}$ Treatments: $1 \times 8=8$ consecutive bails activated; $2 \times 4=2$ sets of 4 consecutive bails activated; $4 \times 2=4$ sets of 2 consecutive bails activated; $8 \times 1=$ every alternate bail activated (Figure 2 ).

The assumptions of REML or Poisson regression were not valid for the model of duration of cow idle times, and, therefore, a negative binomial model was built instead. Neither feed availability nor treatment had any significant effect on duration of idle times.

\section{System Factors Resulting in Occurrence of Idle Events}

The results of the final generalized linear mixed model showed a significant effect of bail activation treatment and availability of feed on the incidence of systemrelated idle times. As shown in Table 6 , treatment $4 \times 2$ was 5.14 times more likely to cause a system-related idle time compared with treatment $1 \times 8$, whereas treatment $8 \times 1$ resulted in the lowest incidence of idle time events related to system factors. The availability of feed also resulted in an increased number of system-related idle times.

No significant effect was observed for the bail activation sequence $(P=0.21)$ or the availability of feed $(P$ $=0.10)$ on the duration of idle time events.

\section{Harvesting Rate}

Treatment $8 \times 1$ resulted in a significant decrease of the system harvesting rate $(\mathrm{kg}$ per minute of robotic operation time; $\mathrm{kg} / \mathrm{min}$ ) compared with the other treatments (Figure 3). The availability of feed did not affect the harvesting rate in the final model.

\section{DISCUSSION}

Utilization of available bails was not influenced by bail activation sequence. However, the availability of feed had a significant effect on bail utilization. However, the availability of feed had a significant effect on bail utilization, despite the incorporation of a $5-\mathrm{d}$ habituation period after removal of the feed. It should be noted that all cows were familiar with receiving feed on the RR prior to the study. Although the effect of feed availability on inexperienced cows adapting to the system is unknown, the results suggest that an ability to provide feed on the RR would likely be beneficial and should be included in the design of the RR dairy.

Table 6. Final generalized linear mixed model to investigate the probability of an idle event occurring due to system factors ${ }^{1}$

\begin{tabular}{llcccc}
\hline Effect & Category & $\begin{array}{c}\text { Parameter } \\
\text { estimate }\end{array}$ & $\mathrm{SE}$ & $\begin{array}{c}\text { Odds ratio } \\
(95 \% \mathrm{CI})\end{array}$ & $P$-value \\
\hline Intercept $^{\text {Bail treatment }}{ }^{2}$ & & -1.85 & 0.21 & & $<0.0001$ \\
& $1 \times 8$ & 0.00 & & & \\
& $2 \times 4$ & 0.53 & 0.23 & $1.70(1.09,2.65)$ & \\
& $4 \times 2$ & 1.64 & 0.22 & $5.14(3.31,7.00)$ & \\
Feed availability & $8 \times 1$ & -2.21 & 0.40 & $0.11(0.05,0.24)$ & $<0.0001$ \\
& No feed & 0 & & & \\
& Feed & 0.90 & 0.20 & $2.46(1.67,3.62)$ & \\
\hline
\end{tabular}

${ }^{1}$ Block and day nested in block were included as random effects.

${ }^{2}$ Treatments: $1 \times 8=8$ consecutive bails activated; $2 \times 4=2$ sets of 4 consecutive bails activated; $4 \times 2=4$ sets of 2 consecutive bails activated; $8 \times 1=$ every alternate bail activated (Figure 2 ). 


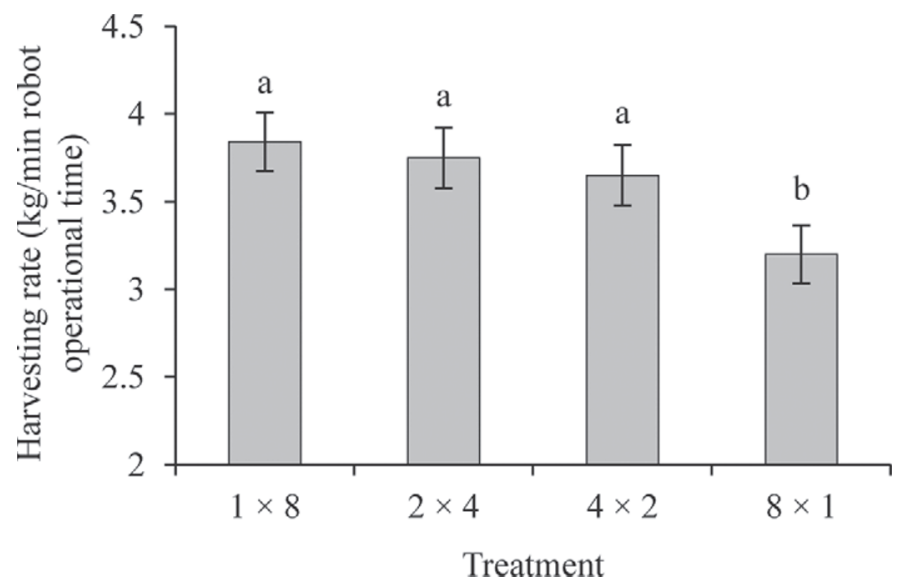

Figure 3. Robot operational efficiency as assessed by harvesting rate per treatment: 8 consecutive bails activated $(1 \times 8) ; 2$ sets of 4 consecutive bails activated $(2 \times 4) ; 4$ sets of 2 consecutive bails activated $(4 \times 2)$; and every alternate bail activated $(8 \times 1)$. Vertical bars indicate SEM and different letters indicate a significant treatment effect at $\alpha$ $=0.05$ level

A study by Prescott et al. (1998) suggested that feeding in the AMS is likely necessary to motivate cows to visit an AMS. Their research showed that feed was significantly more rewarding for a cow than milking itself. A more recent study (Melin et al., 2006) concluded that both milking and feeding acted as rewards; however the motivation to access feed had a higher priority than the motivation of being milked.

Similar negative effects were found for the availability of feed when investigating the incidence of cows hesitating to enter the RR. No significant effects were found by bail activation sequence, indicating that cow traffic was not affected by different bail activation sequences.

Different bail activation sequences significantly affected the probability of system-related idle times, as did feed availability. Treatment $4 \times 2$ resulted in the highest proportion of system-related idle times. This was likely caused by the fact that this treatment had 4 bails that did not have a buffer period. Therefore, cows should be granted access to the platform as soon as possible after a rotation to minimize the effect on cow traffic. In other words, all bail activation configurations should allow cows to access the platform during the buffer period when the TPM or ACA are operating. Treatment $8 \times 1$ had the smallest incidence of systemrelated idle times, as cows were always able to use the buffer period of the system, and the occurrence of cows that were still being milked as they approached the exit area of the platform was very low-particularly compared with treatment $1 \times 8$. During treatment $1 \times 8$, we observed 9 incidences when a cow was still being milked as she approached the exit area. This was predominantly caused by the fact that cows that entered the sixth, seventh, or eighth consecutive active bails (see Figure 2) were rotated to the exit area promptly as the subsequent bails were deactivated, and did not wait for cow entry or TPM and ACA operations. However, although we noted a significant effect of system-related idle times on the system utilization, the magnitude of the effect of cow-related idle times had a greater overall effect on the system throughput efficiency.

Though cow traffic was largely unaffected, harvesting efficiency was significantly affected by the bail activation sequence. Harvesting efficiency indicates the potential amount of milk harvested per minute of robot operation time. The robotic devices of the RR operated most efficiently when consecutive bails were active. This was because the 2 robots (TPM and ACA) were operating simultaneously when at least 2 cows were positioned in consecutive bails, which reduced the handling time and improved the harvesting rate. This resulted in a lower harvesting rate for treatment $8 \times 1$ compared with the other treatments - particularly treatment $1 \times 8$-as a direct result of the number of simultaneous robot operations conducted. The availability of feed would also be expected to affect the system harvesting rate as a direct result of a higher proportion of the available bails being occupied and, therefore, more robot operations being conducted simultaneously. The capacity of the single-box AMS is limited by the fact that the robotic arm cannot attend to any other cows during the entire milk harvesting session of an individual cow. This lowers the harvesting rate, presented as total milk harvested per day divided by the total crate time (when a cow is present in the AMS crate), which is commonly reported to be around 1.25 to $1.85 \mathrm{~kg} / \mathrm{min}$ (de Koning, 2011). A study by Davis et al. (2008) showed an increased harvesting rate from 1.74 to $2.08 \mathrm{~kg} / \mathrm{min}$ when the handling time was reduced by not using the premilking teat cleaning function of the robot. The fact that the robotic arm in the $\mathrm{RR}$ does not remain with the cow during the entire milking process results in a higher potential throughput compared with traditional or commercially available AMS units. The results presented here show that harvesting rates up to $3.85 \mathrm{~kg} /$ min were recorded in this study with the prototype RR with $50 \%$ of the bails enabled.

Although a high harvesting rate $(\mathrm{kg} / \mathrm{min}$ of robotic operation time) was observed in this study, the actual number of cows milked and milk harvested per hour achieved with voluntary cow traffic was considerably lower than the potential. Although the harvesting rate is higher than that achievable with traditional AMS, we recognize that both AMS and RR are extremely reliant on constant and consistent cow traffic if the potential number of milkings and milk harvesting volumes are to be realized on farm. It should also be noted that 
the number of robots installed (1 or 2 each of the TPM and ACA), the configuration of the commercial RR (24 vs. 16 bail) and management practices (voluntary vs. batch cow traffic) will all likely have a significant effect on the throughput achieved on farm. Kolbach et al. (2013) reported a potential throughput of 48 cows/h with the 16-bail prototype RR that was used in this study. The potential and milk harvesting rate presented here are encouraging indicators of the high throughput potential of the RR compared with the traditional AMS box units.

It is important to note that all data presented in this manuscript pertain directly to the prototype 16-bail RR. With ongoing development, both before and after commercialization, the potential exists for the technology to improve with regard to efficiency and functionality. This means that the specific results, such as the harvesting rates presented in this study, may become less aligned with data generated on commercial farms in the future.

\section{CONCLUSIONS}

We concluded that when half of the total bails were deactivated (to simulate periods of underutilization), the sequence of active bails per se did not affect cow traffic onto the RR platform. The application of this finding is most relevant for periods when the herd size and total number of anticipated milkings are lower than the system capacity. The negative results of the absence of feed upon entry to the RR indicate that cow traffic onto the platform was improved when feed was available. This suggests that when cows are accustomed to receiving feed during milking, regular provision of feed is important to ensure voluntary movement of cows onto the RR while avoiding delays related to cow traffic. We noted advantages through activating simultaneous bails, rather than alternate bails, to result in an increased milk harvesting rate through a higher proportion of robot operations being conducted simultaneously. Consecutive bails activated in combination with feed will result in an increased efficiency of operation while managing the $\mathrm{RR}$ in an underused setting.

\section{ACKNOWLEDGMENTS}

This work was carried out within the FutureDairy program. We acknowledge the investors: Dairy Australia, Melbourne, Australia; DeLaval, Tumba, Sweden; NSW Department of Primary Industries, Orange, Australia; the University of Sydney, Australia.. We also thank Mikael Karttunen (DeLaval, Camden, Australia) for his technical support of the RR and the FutureDairy team for their assistance.

\section{REFERENCES}

Bach, A., C. Iglesias, S. Calsamiglia, and M. Devant. 2007. Effect of amount of concentrate offered in automatic milking systems on milking frequency, feeding behavior, and milk production of dairy cattle consuming high amounts of corn silage . J. Dairy Sci. 90:5049-5055.

Davis, K. L., W. J. Fulkerson, and S. C. Garcia. 2007. Automatic milking. Pages 120-131 in Proc. Univ. Sydney Dairy Res. Fdn. Dairy Research Foundation, Camden, Australia.

Davis, K. L., W. J. Fulkerson, S. C. Garcia, D. Dickeson, and I. M. Barchia. 2008. Premilking teat preparation for Australian pasturebased cows milked by an automated milking system. J. Dairy Sci. 91:2604-2609.

de Koning, C. J. A. M. 2011. Milking machines-Robotic milking. Pages 952-958 in Encyclopedia of Dairy Science Academic Press, San Diego, CA.

Halachmi, I., S. Ofir, and J. Miron. 2005. Comparing two concentrate allowances in an automatic milking system. Anim. Sci. 80:339343.

Jago, J., P. Copeman, K. Bright, D. McLean, I. Ohnstad, and M. Woolford. 2002. An innovative farm system combining automated milking with grazing. Pages $115-119$ in Proc. New Zealand Soc. Anim. Prod. DairyNZ, Hamilton, New Zealand.

Kolbach, R., K. L. Kerrisk, and S. C. Garcia. 2013. The effect of premilking with a teat-cup-like device, in a novel robotic rotary, on attachment accuracy and milk removal. J. Dairy Sci. 96:360-365.

Melin, M., G. G. N. Hermans, G. Pettersson, and H. Wiktorsson. 2006. Cow traffic in relation to social rank and motivation of cows in an automatic milking system with control gates and an open waiting area. Appl. Anim. Behav. Sci. 96:201-214.

Prescott, N. B., T. T. Mottram, and A. J. F. Webster. 1998. Relative motivations of dairy cows to be milked or fed in a y-maze and an automatic milking system . Appl. Anim. Behav. Sci . 57:23-33.

Stefanowska, J., A. H. Ipema, and M. M. W. B. Hendriks. 1999. The behaviour of dairy cows in an automatic milking system where selection for milking takes place in the milking stalls. Appl. Anim. Behav. Sci . 62:99-114.

\section{APPENDIX 1}

The RR will go through a series of actions to result in a cow being milked and released back into the herd. The detailed operational process of the RR is as follows:

(1) A cow presents herself at the entry and is electronically recognized by her neck transponder.

(2) If the first bail position (termed "buffer zone" and numbered as bail 16 in Figure 1) is already occupied, the cow waiting at the gate will not gain access until the next available bail (bail 1 in Figure 1) rotates to the entry gate position; this will not happen until all robot actions are complete. Cows receive their first $\sim 150$-g portion of pelleted concentrate while in the buffer zone position.

(3) When robot actions are complete, the cow is rotated toward the first robot, the TPM zone (shown as bail 15 in Figure 1), where teats are cleaned, foremilk is removed and the milk let down is stimulated with a teat-cup-like cleaning device while a second portion of $\sim 150 \mathrm{~g}$ of feed is given and the bail that is now located in the buffer zone accepts another cow. 
(4) At the same time, teat cups are attached to the cow positioned at the ACA zone (in front of the ACA robot; shown as bail 14 in Figure 1).

(5) When both robots, the TPM and ACA are finished (and the second cow has entered the platform at the buffer zone), a rotation step will take the prepared cow to the ACA position (show as bail 14 in Figure 1).

(6) At the ACA zone teat cups are collected from a magazine 2 at a time and are attached indi- vidually - every teat has a separate in-line milk meter that monitors milk volume (flow) and milk quality (conductivity).

(7) The cow is rotated toward the exit of the RR platform in a step-wise fashion, where she is expected to leave the platform (subsequent cows enter the platform and go through the same premilking and cup attachment process described above). 